Mirtazapine for chronic breathlessness? A review of mechanistic insights and therapeutic potential

N Lovell ${ }^{1}$, A Wilcock ${ }^{2}$, S Bajwah ${ }^{1}$, SN, Etkind ${ }^{1}$, CJ Jolley ${ }^{3}$, M Maddocks $^{1}$, IJ Higginson ${ }^{1}$

1. Cicely Saunders Institute of Palliative Care, Policy and Rehabilitation, King's College London, Bessemer Road, London SE5 9PJ, United Kingdom

2. University of Nottingham, Palliative Medicine, Hayward House Specialist Palliative Care Unit, Nottingham University Hospitals NHS Trust, Nottingham, NG5 1PB, United Kingdom

3. Centre for Human \& Applied Physiological Sciences, School of Basic \& Medical Biosciences, Faculty of Life Sciences \& Medicine, King's College London SE1 1UL, United Kingdom

*Corresponding Author Details:

Natasha Lovell. Email: Natasha.lovell@kcl.ac.uk. Tel: 02078485773. 


\section{Conflict of Interest statement:}

The authors declare that they have no conflict of interest.

\section{Author Contributions:}

Concept and development: NL, AW, SB, MM, IJH

Drafting: NL, AW, SE, CJJ, SB, MM, IJH

Review and approval of final draft: NL, AW, SE, CJJ, SB, MM, IJH

\section{Funding:}

This work is independent research funded by Marie Curie, Cicely Saunders International and The Atlantic Philanthropies in the Cicely Saunders Institute Fellowship Programme. NL is completing a training fellowship funded by Cicely Saunders International and Marie Curie (Grant Number A18859). MM is supported by an NIHR Career Development Fellowship (CDF-2017-10-009) and NIHR CLARHC South London. IJH is an NIHR Emeritus Senior Investigator and is supported by NIHR CLARHC South London. This research was supported by the Collaboration for Leadership in Applied Health Research and Care (CLAHRC) South London, which is part of the National Institute for Health Research (NIHR), and is a partnership between King's Health Partners, St. George's, University London and St George's Healthcare NHS Trust. The views expressed are those of the authors and not necessarily those of the NHS, the NIHR or the Department of Health. 


\begin{abstract}
Introduction

Chronic breathlessness is a common and distressing symptom of advanced disease with few effective treatments. Central nervous system mechanisms are important in respiratory sensation and control. Consequently, drugs which may modify processing and perception of afferent information in the brain, may have a role. Antidepressants have been proposed, however current evidence is limited. Of potentially suitable antidepressants, mirtazapine is an attractive option given its tolerability profile, low cost and wide availability, along with additional potential benefits.
\end{abstract}

\title{
Areas covered
}

The paper provides an overview of the physiology of breathlessness, with an emphasis on central mechanisms, particularly the role of fear circuits and the associated neurotransmitters. It provides a potential rationale for how mirtazapine may improve chronic breathlessness and quality of life in patients with advanced disease. The evidence was identified by a literature search performed in PubMed through to October 2018.

\section{Expert commentary}

Currently, there is insufficient evidence to support the routine use of antidepressants for chronic breathlessness in advanced disease. Mirtazapine is a promising candidate to pursue, with definitive randomised controlled trials required to determine its efficacy and safety in this setting.

\section{Key words}

chronic lung disease, chronic breathlessness, breathlessness perception, mirtazapine, antidepressant 


\section{Introduction}

Breathlessness is a common and distressing symptom of advanced disease, affecting most people living with chronic obstructive pulmonary disease (COPD) and interstitial lung disease (ILD) [1, 2, 3]. Breathlessness is 'a subjective experience of breathing discomfort that consists of qualitatively distinct sensations that vary in intensity'[4]. Chronic breathlessness has recently been defined as 'breathlessness that persists despite optimal treatment of the underlying pathophysiology and results in disability for the patient' [5]. Refractory breathlessness is another term used to describe breathlessness that persists despite optimal treatment of the underlying condition[6]. Chronic or refractory breathlessness is often accompanied by episodic breathlessness, defined as 'a severe worsening of breathlessness intensity or unpleasantness beyond usual fluctuations in the patient's perception'[7].

Whilst non-pharmacological interventions take priority initially, the more severe the breathlessness is, the more likely the need for pharmacological treatment $[8,9]$. Currently no drugs are licenced for chronic or refractory breathlessness[10]. The benefit of oxygen in the absence of hypoxia remains unclear with evidence from larger trials required[11, 12], and whilst benzodiazepines are sometimes used to treat breathlessness-related anxiety, there is no evidence that they relieve breathlessness itself in people with advanced cancer and COPD[13]. There is evidence to support the use of parental and oral opioids[14]. However, optimal dosing, titration and potential issues arising from long-term use and safety remain to be determined[13, 15, 16, 17, 18]. Further, not all patients are suitable for, want to take, or respond to opioids, and clinicians can be reluctant to prescribe them[17, 19, 20, 21 , 22]. Thus, new effective treatments are required.

Breathlessness is multidimensional, comprising distinct sensory (intensity / qualitative) and affective/cognitive components that can be manipulated and measured independently of each other[23, 24, 25, 26]. Consequently, drugs which may modify processing and perception of afferent information in the brain, may have a role. This may be a mechanism of action for opioids. Antidepressants have been proposed, however current evidence is limited[27, 28, 29, 30, 31]. Recently published data found no benefit when sertraline (a selective serotonin reuptake inhibitor antidepressant (SSRI)) was compared to placebo in patients with a Modified Medical Research Council (mMRC) Dyspnea Scale grade of two or above[31]. Mirtazapine is a common antidepressant which is acceptable in the advanced disease population. Its actions on multiple relevant neurotransmitter systems distinguish it from other antidepressants, and this, alongside a favourable side effect profile, make it a promising candidate to explore in the treatment of chronic breathlessness. 
The paper reviews the physiology of breathlessness, with an emphasis on central mechanisms, in particular the role of fear circuits, and the associated neurotransmitters. We consider how one particular antidepressant, mirtazapine may improve chronic breathlessness and quality of life in patients with advanced disease. The evidence was identified by searching for key terms in published databases including PubMed through to October 2018. Additional papers were identified through citation searches and expert opinion. Evidence was included based on the consensus of the research team regarding quality and relevance to the review question. Whilst we recognise the relationship between depression, anxiety and breathlessness[32, 33, 34, 35, 36, 37, 38, 39], exploring how treatment of a concurrent mood disorder may affect chronic breathlessness is beyond the scope of this paper. This paper focuses on how mirtazapine may affect the experience of breathlessness in those both with, and without a mood disorder.

\section{Mechanisms of breathlessness}

\subsection{Physiology}

The mechanisms of breathlessness are complex and incompletely understood, but are thought to encompass interactions between multiple physiological, psychological, social, and environmental factors $[4,40]$. There is evidence that qualitative appraisal of respiratory sensations is mechanistically distinct to breathlessness intensity[23, 41].

Theories about breathlessness perception can generally be divided into two categories. In the first, breathlessness is explained as being driven by cortical integration of an ascending copy of the descending motor activity to respiratory muscles (the 'neural respiratory drive' (NRD)) together with feedback from respiratory sensory afferents[4]. The second category presents the theory of interoception, where the brain generates sensations (priors) based on expectations learnt from past experience. These priors are then compared against incoming afferent signals to generate a symptom experience[48].

Patient-reported breathlessness intensity in chronic respiratory disease has been shown to be closely related to increased levels of NRD, reflecting the increased load on, and/or reduced capacity of, the respiratory muscles as a consequence of impaired respiratory mechanics[42, 43, 44, 45]. These observations support the hypothesis that the perception of breathlessness intensity in humans is mechanistically linked to the awareness of increased NRD as sensed by increased 'central 
corollary discharge', which refers to the simultaneous projection of resultant neural signals from the motor cortex and/or respiratory centres of the brainstem to the respiratory muscles and sensory areas of the brain[46, 47]. Distinct sensations of breathlessness, most importantly "work/effort", "air hunger" ("unsatisfied inspiration" /"urge to breathe") and "chest tightness", are however likely to originate from central integration of differing sources of afferent information[4, 40,45].

Neuroimaging studies are beginning to elucidate complex interactions between neural networks underpinning emotional and sensory perception of breathlessness, offering important insights into the role of higher cortical processing in respiratory sensation[48, 49, 50,51,52,53]. Initial studies of induced breathlessness in healthy volunteers have confirmed activation of the insula, amygdala and anterior cingulate cortex, areas of the brain known to be active during perceived threat, with processing of the affective unpleasantness of perceived dyspnea in the right anterior insula and amygdala[48, 49, 50,53]. In addition it has recently been shown that simply observing dyspnoea in others can elicit dyspnoea, negative affect and increased brain responses in the absence of physiological changes[54]. This supports the idea that central brain processes can elicit or intensify the experience breathlessness. More recently, studies have included people with chronic lung disease. A feasibility study of magnetoencephalography scanning found increased $\beta$ band activity indicating constant 'vigilance', or an anticipatory state with regard to peripheral respiratory stimuli[55], and preliminary findings from a fMRI feasibility study suggest that the degree of disconnection between the left anterior insula and dorsal anterior cingulate cortex correlates with unpleasantness/discomfort of breathlessness (Meng D, Cottam W, Weller J, et al. European Society of Radiology Congress; 2018; Vienna, Austria).

\subsection{Fear circuits and the perception of threat}

The regions identified in the above studies closely relate to neurological circuits involved in threat perception and the experience of fear $[48,50,53]$. The ability to perceive threat is vital for survival. The response to threat is multi-faceted and regulated by numerous neuronal connections entering and leaving the amygdala (Figure 1). These pathways are responsible for the motor and endocrine features of the 'fight or flight response', combined with the conscious perception of fear[56, 57]. The fight or flight response is mediated by neuronal transmission from the amygdala to the periaqueductal grey area. Ongoing transmission to the hypothalamus and areas of the brainstem results in a rapid release of cortisol, and an autonomic response is triggered by the locus coerulus which can include an increase in heart rate and blood pressure[57]. The emotional response to a 
threat involves neural transmission between the amygdala, the orbitofrontal cortex and the anterior cingulate cortex [58]. Given the potential role of fear circuits in the perception of breathlessness, drugs acting within these regions such as mirtazapine may be beneficial. This is further discussed in section 3.2 .

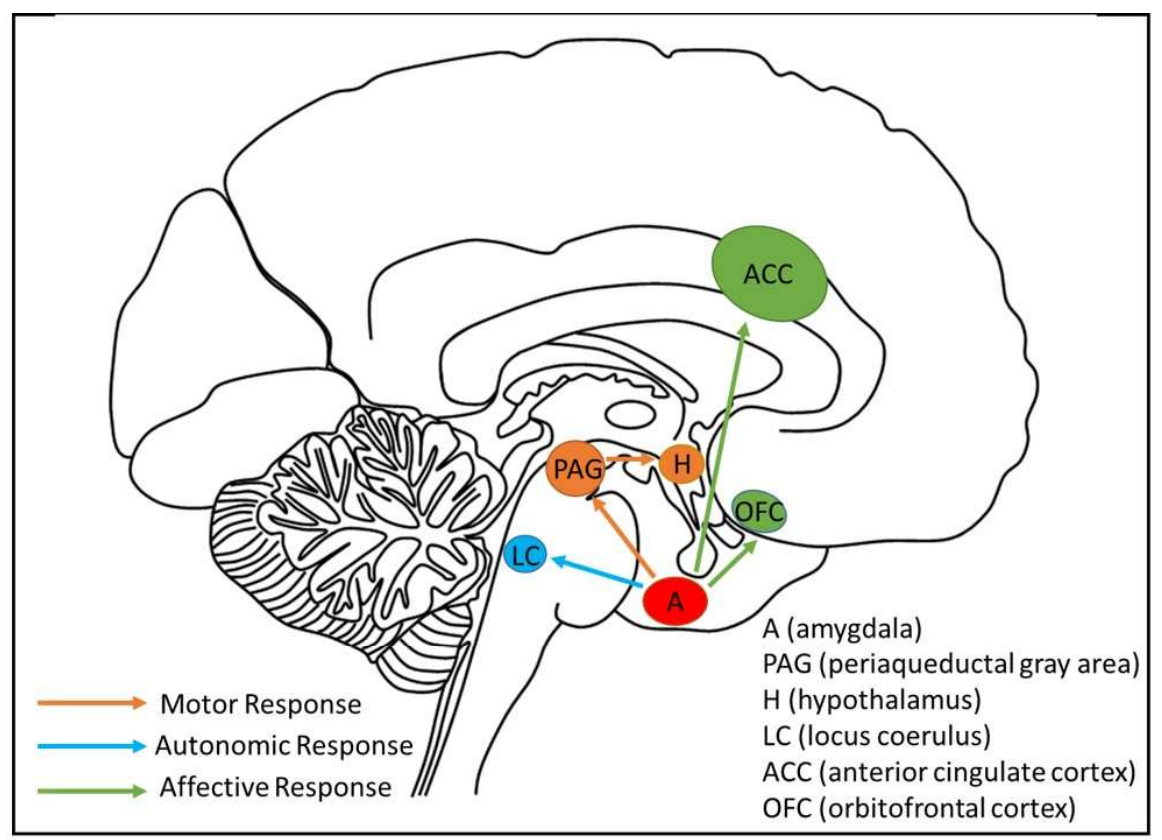

Figure 1: Fear circuits and the amygdala

Motor response as neuronal transmission from the amygdala to the periaqueductal grey area, hypothalamus and areas of the brainstem.

Autonomic response triggered by the locus coerulus.

Affective response involves neural transmission between the amygdala, the orbitofrontal cortex and the anterior cingulate cortex.

Whilst fear is often experienced and forgotten, the amygdala assimilates stimuli associated with previous fearful situations, and when exposed to this stimuli again, triggers a response (fear conditioning)[57]. This could explain how an episode of breathlessness and severe panic may lead to recurrent panic when the patient is exposed to a similar trigger. During interoception the brain generates sensations referred to as priors based on expectations learnt from a past experience. These priors are then compared against incoming afferent signals to generate a symptom experience[59]. These interactions can be influenced by many factors including fatigue and depression[60], and recent work has demonstrated how a rehabilitation programme for breathlessness can lead to changes in associative learning and the resetting of breathlessness related priors[61]. A number of other factors have been associated with an increased perception of threat including the environment, psychiatric illness, and personality traits $[62,63,64,65]$. 


\subsection{The function of neurotransmitters in breathlessness}

A number of neurotransmitters have been identified as important in breathlessness, in particular, serotonin (5-HT) and norepinephrine (NE). Other neurotransmitters (GABA, dopamine, acetylcholine and NMDA) may also play roles in symptom perception through their contribution to interoceptive processes.

5-HTplays a role in the central control of respiration via multiple receptor subtypes, contributing to chemosensitivity and mediating ventilatory response to changes in $\mathrm{CO}_{2} / \mathrm{pH}$, and by maintaining regulatory function as part of respiratory neuroplasticity[66, 67, 68, 69, 70, 71, 72]. 5-HT also regulates anxiety and panic through connections between the amygdala, and the prefrontal cortex, striatum and thalamus, and may therefore be important in the conscious perception of breathlessness[73]. An inhibitory effect on the amygdala results in suppression of fear circuits and thus drugs which increase $5-\mathrm{HT}$ can reduce levels of anxiety and panic $[57,74]$. Further, the importance of serotonergic modulation is suggested by a reduction in panic following administration of L-5-hydroxytryptophan (the immediate precursor of 5-HT), sertraline or citalopram to patients with panic disorder breathing a mixture containing $35 \% \mathrm{CO}_{2}[75,76]$. However, despite strong evidence of the role of serotonin in respiration, clinical benefit has not yet been demonstrated[31].

NE is important in neuronal connections between the amygdala and the locus coeruleus, the centre involved in generating the physiological response to stress and panic, e.g. increased heart rate, blood pressure and respiratory rate[57]. Whilst the role of NE during an acute stress is hyperactivity, chronic stress (for example in mood disorders) causes hypo-reactivity of the NE system[77], and in animal studies exposure to chronic stress has been correlated with a decrease in the release of NE in the brain, as well as atrophy of NE axonal projections[78, 79]. Further, venoarterial levels of NE and 3-methoxy-4-hydroxyphenylglycol (the metabolite of NE) are significantly lower in people diagnosed with depression compared to controls[80]. In addition a rise in circulating norepinephrine causes relaxation of bronchial muscles and a decrease in fluid secretion from bronchial glands therefore improving respiration[81, 82]. Other neurotransmitters of interest include endorphins[83], cannabinoids and neurokinin[84]. 


\section{Mirtazapine for chronic breathlessness}

\subsection{Mechanism of action}

Mirtazapine is a noradrenergic and specific serotonergic antidepressant (NaSSA) which is well tolerated, relatively cheap and available in generic form worldwide[85, 86, 87]. Mirtazapine antagonizes $\alpha_{2}$ auto- and hetero-receptors resulting in enhanced noradrenergic transmission and reduced inhibition of 5-HT release (Figure 2)[88, 89]. NE release in the raphe nuclei also stimulates postsynaptic $\alpha_{1}$ receptors of neuronal cell bodies, causing 5-HT release from downstream axon terminals such as those in the cortex (Figure 2)[57]. This enhanced noradrenergic and serotonergic transmission is mostly responsible for the antidepressant and anxiolytic effects of mirtazapine.

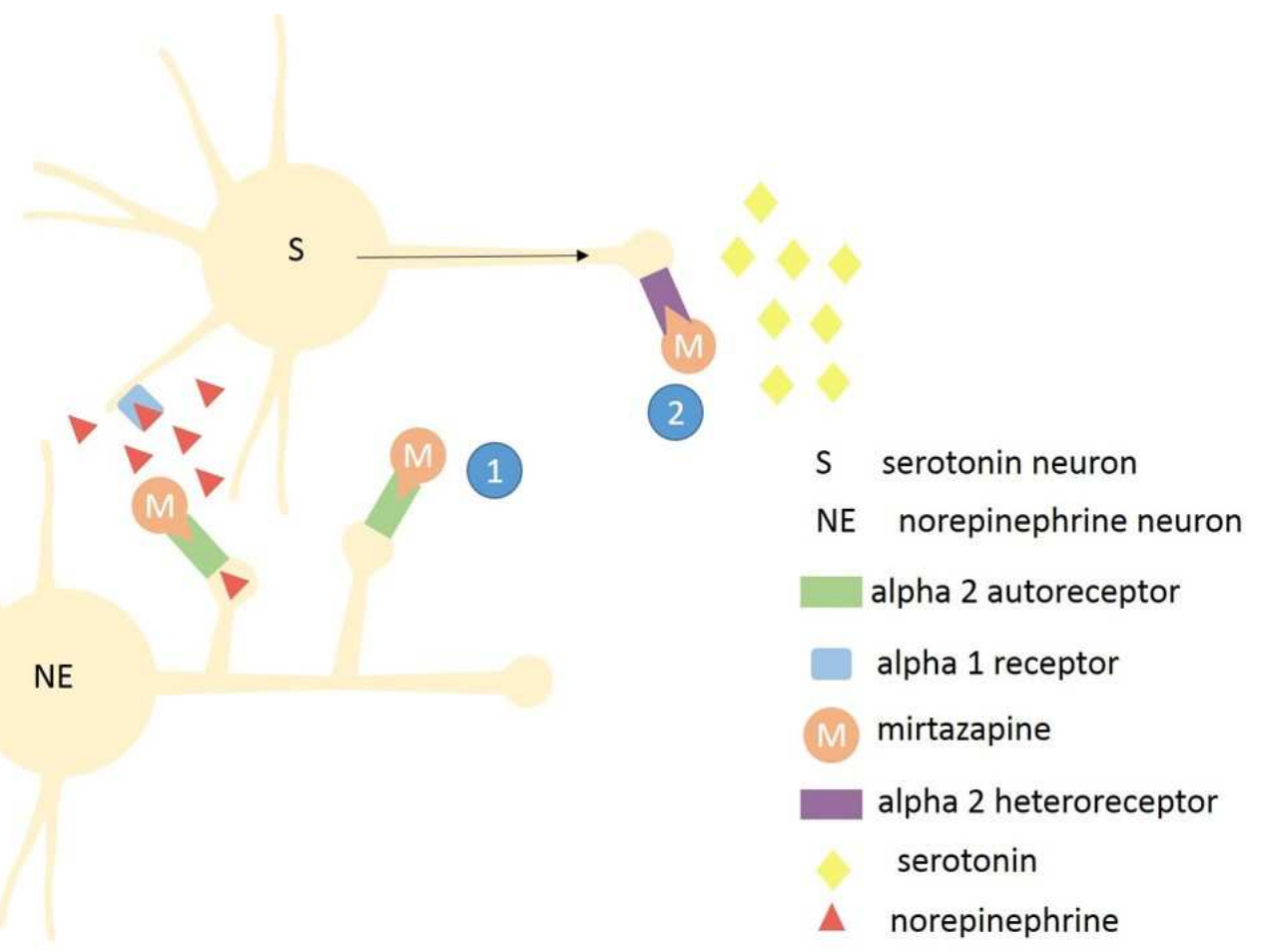

Figure 2: Mechanism of action of mirtazapine: (1) Blockade of $\alpha-2$ autoreceptors increases synaptic norepinephrine, stimulating $\alpha 1$ receptors and resulting in serotonin release. (2) Blockade of $\alpha 2$ heteroreceptors reduces inhibition of serotonin release (adapted from Stahl's essential psychopharmacology 2013.) 
Mirtazapine also antagonizes $5-\mathrm{HT}_{2}$ and $5-\mathrm{HT}_{3}$ receptors and as a consequence, unlike with SSRIs, gastro-intestinal effects (e.g. nausea, diarrhoea) and sexual dysfunction are uncommon[89]. It is a potent antagonist of histamine $\mathrm{H}_{1}$ receptors[88] explaining the most common side effects of somnolence, increased appetite and weight gain[86]. At higher doses, sedation is less commonly reported, possibly due to increased noradrenergic transmission counteracting the antihistamine effect. It is not known to be associated with a reduced respiratory drive which is an advantage in chronic lung disease management[90]. It is worth noting that mirtazapine is metabolized by CYP1A2, CYP2D6, and CYP3A4 and caution should be taken with concurrent use of drugs which inhibit or induce these enzymes. This should be considered in a population likely to have high levels of comorbidity and polypharmacy[91].

Mirtazapine is authorised for the treatment of depression; additional beneficial effects on anxiety, psychological distress and sleep disturbance are seen compared with placebo[92]. Mirtazapine is significantly more effective at treating depression at two weeks compared to selective serotonin reuptake inhibitors (SSRIs) and serotonin-noradrenaline reuptake inhibitors (SNRIs) [93]. A systematic review and meta-analysis of the efficacy and acceptability of 21 antidepressant drugs in adults with depression found that mirtazapine had a higher response rate and lower dropout rate than the other antidepressants when compared with placebo[85]. Although an anxiolytic effect has been demonstrated for mirtazapine[94], it is not currently authorised for the treatment of anxiety disorders. It is however, free from the initial worsening of anxiety or agitation that can occur with SSRIs.

\subsection{Mirtazapine as a treatment for breathlessness and other symptoms in chronic lung disease}

Mirtazapine may benefit chronic breathlessness indirectly through known effects on mood. However, mirtazapine may also have direct beneficial effects, through inhibition of fear circuits and fear conditioning, and by causing bronchodilation. Even in healthy volunteers, mirtazapine has rapid effects. Two hours after a single dose of mirtazapine, there are changes in keeping with a decreased processing of threatening stimuli, an increased processing of positive or rewarding stimuli and reduced self-referential processing[95, 96, 97, 98]. At the neural level, there are decreased right amygdala-hippocampal and fronto-striatal responses to fearful vs. happy facial expressions, increased responses of the parietal cortex to a reward task, and reduced responses in the dorsomedial prefrontal cortex, ventromedial prefrontal cortex and ventral anterior cingulate cortex, considered the self-referential network[95, 97, 98]. In response to more natural and complex 
emotional stimuli, mirtazapine leads to large-scale changes spanning limbic, sensorimotor and cortical midline structures[99]. Taken together, these changes suggest that mirtazapine impacts rapidly on neural circuits involved in vigilance and the perception of, and the emotional response to, unpleasant stimuli (of which breathlessness is one) through the process of interoception.

In addition mirtazapine may benefit additional symptoms common in this population. Mirtazapine is a potent antagonist of histamine and therefore common side effects including somnolence, increased appetite and weight gain may be of benefit to patients with chronic lung disease who frequently report sleep disturbance, poor appetite and weight loss[86, 88, 100, 101]. Further, depression, anxiety and panic are common in this group, and associated with increased healthcare utilisation[32, 33, 34, 35, 36, 37, 38]. Generally, mood disorders are underdiagnosed and thereby undertreated in the medically ill. In a large study of 1334 people with chronic lung disease, $80 \%$ screened positive for depression, anxiety or both, yet only $31 \%$ were receiving treatment for anxiety or depression[39]. Thus, by treating an underlying anxiety or depressive mood disorder, mirtazapine may have beneficial effects on the emotional and behavioural response to chronic breathlessness[57].

\section{Conclusions}

In addition to its known effects on mood, Mirtazapine has effects that are potentially beneficial for the management of chronic breathlessness, predominantly by modifying the processing and perception of afferent information in the brain. Mirtazapine is an attractive candidate to explore as is well-tolerated, affordable and available, with a quick onset of action. Antagonism of 5-HT 2 and 5$\mathrm{HT}_{3}$ receptors means mirtazapine does not share some of the common side effects of other commonly used antidepressants, and antagonism of $\mathrm{H} 1$ receptors can result in improved appetite and sleep which may be beneficial in patients with advanced disease. High quality evidence from definitive randomised controlled trials is needed to determine the effectiveness of mirtazapine, on the distressing and common symptom of chronic or refractory breathlessness.

\section{Expert Commentary}

Chronic breathlessness remains a common and distressing symptom of advanced disease with few effective treatment options. Whilst there is evidence to support the use of parental and oral opioids, not all patients report benefit, and long term safety data is currently lacking. The goal should be to 
identify new effective treatments so that clinicians and patients have more options. In recent years thinking has moved towards drugs which may modify the processing and perception of afferent information in the brain, such as antidepressants. The repurposing of existing inexpensive medications that are off patent and widely available is an attractive option, however, data remains limited. Mirtazapine is a promising candidate, but there is currently insufficient evidence to support use to treat breathlessness in clinical practice. The concern is that clinicians may nevertheless opt to give antidepressants including mirtazapine for chronic breathlessness, particularly as they are inexpensive and off patent. It is important to ensure that patients are not being given medicines that are ineffective in treating breathlessness. Blinded randomised controlled trials are therefore urgently needed to provide appropriate evidence on the effectiveness of mirtazapine in reducing breathlessness in patients with and without depression and anxiety.

\section{Five-year view}

In the next 5 years we anticipate that blinded randomised trials will be conducted to determine the effectiveness of antidepressants including mirtazapine to treat chronic breathlessness. Results of these trials will aid national and international clinical guidelines and policy recommendations by providing a much needed evidence base.

\section{Key issues}

- Chronic breathlessness remains a common and distressing symptom of advanced disease with few effective treatment options

- Whilst there is evidence to support the use of parental and oral opioids, not all patients report benefit, and long term safety data is currently lacking

- Therefore new effective treatments are urgently needed

- In recent years thinking has moved towards drugs which may modify the processing and perception of afferent information in the brain, such as antidepressants

- Mirtazapine is a promising candidate, but there is currently insufficient evidence to support routine use to treat breathlessness in clinical practice

- Definitive randomised controlled trials are needed to provide evidence to guide clinical practice 


\section{Conflict of Interest statement:}

The authors declare that they have no conflict of interest. 


\section{References}

1. Solano JP, Gomes B, Higginson IJ. A comparison of symptom prevalence in far advanced cancer, AIDS, heart disease, chronic obstructive pulmonary disease and renal disease. Journal of pain and symptom management. 2006 Jan;31(1):58-69. doi: 10.1016/j.jpainsymman.2005.06.007. PubMed PMID: 16442483; eng.

2. Moens K, Higginson IJ, Harding R. Are there differences in the prevalence of palliative carerelated problems in people living with advanced cancer and eight non-cancer conditions? A systematic review. Journal of pain and symptom management. 2014 Oct;48(4):660-77. doi: 10.1016/j.jpainsymman.2013.11.009. PubMed PMID: 24801658; eng.

3. Bajwah S, Higginson IJ, Ross JR, et al. Specialist palliative care is more than drugs: a retrospective study of ILD patients. Lung. 2012 Apr;190(2):215-20. doi: 10.1007/s00408-0119355-7. PubMed PMID: 22218887; eng.

4. Parshall MB, Schwartzstein RM, Adams L, et al. An official American Thoracic Society statement: update on the mechanisms, assessment, and management of dyspnea. American journal of respiratory and critical care medicine. 2012 Feb 15;185(4):435-52. doi: 10.1164/rccm.201111-2042ST. PubMed PMID: 22336677; PubMed Central PMCID: PMCPMC5448624. eng.

5. Polkey MI, Lyall RA, Yang K, et al. Respiratory Muscle Strength as a Predictive Biomarker for Survival in Amyotrophic Lateral Sclerosis. American Journal of Respiratory and Critical Care Medicine. 2017;195(1):86-95. doi: 10.1164/rccm.201604-08480C. PubMed PMID: 27494149.

6. Booth $\mathrm{S}$, Bausewein $\mathrm{C}$, Higginson I, et al. Pharmacological treatment of refractory breathlessness. Expert review of respiratory medicine. 2009 Feb;3(1):21-36. doi: 10.1586/17476348.3.1.21. PubMed PMID: 20477280; eng.

7. Simon ST, Weingartner V, Higginson IJ, et al. Definition, categorization, and terminology of episodic breathlessness: consensus by an international Delphi survey. Journal of pain and symptom management. 2014 May;47(5):828-38. doi: 10.1016/j.jpainsymman.2013.06.013. PubMed PMID: 24095285; eng.

8. Maddocks M, Lovell N, Booth S, et al. Palliative care and management of troublesome symptoms for people with chronic obstructive pulmonary disease. Lancet (London, England). 2017 Sep 2;390(10098):988-1002. doi: 10.1016/s0140-6736(17)32127-x. PubMed PMID: 28872031; eng.

9. McCarthy $B$, Casey D, Devane $D$, et al. Pulmonary rehabilitation for chronic obstructive pulmonary disease. Cochrane Database of Systematic Reviews. 2015 (2). doi: 10.1002/14651858.CD003793.pub3. PubMed PMID: CD003793.

10. Mahler DA, Sethi S. To Improve COPD Care: A New Instrument Is Needed to Assess Dyspnea. Chest. 2018 Aug;154(2):235-237. doi: 10.1016/j.chest.2018.02.020. PubMed PMID: 30080497; eng.

11. Abernethy AP, McDonald CF, Frith PA, et al. Effect of palliative oxygen versus room air in relief of breathlessness in patients with refractory dyspnoea: a double-blind, randomised controlled trial. Lancet (London, England). 2010 Sep 4;376(9743):784-93. doi: 10.1016/s0140-6736(10)61115-4. PubMed PMID: 20816546; PubMed Central PMCID: PMCPMC2962424. eng.

12. Uronis HE, Ekstrom MP, Currow DC, et al. Oxygen for relief of dyspnoea in people with chronic obstructive pulmonary disease who would not qualify for home oxygen: a systematic review and meta-analysis. Thorax. 2015 May;70(5):492-4. doi: 10.1136/thoraxjnl-2014205720. PubMed PMID: 25472664; eng.

13. Simon ST, Higginson IJ, Booth S, et al. Benzodiazepines for the relief of breathlessness in advanced malignant and non-malignant diseases in adults. The Cochrane database of systematic reviews. 2016 Oct 20;10:Cd007354. doi: 10.1002/14651858.CD007354.pub3. PubMed PMID: 27764523; eng. 
14. Ekstrom M, Bajwah S, Bland JM, et al. One evidence base; three stories: do opioids relieve chronic breathlessness? Thorax. 2018 Jan;73(1):88-90. doi: 10.1136/thoraxjnl-2016-209868. PubMed PMID: 28377491; eng.

15. Barnes H, McDonald J, Smallwood N, et al. Opioids for the palliation of refractory breathlessness in adults with advanced disease and terminal illness. The Cochrane database of systematic reviews. 2016 Mar 31;3:Cd011008. doi: 10.1002/14651858.CD011008.pub2. PubMed PMID: 27030166; eng.

16. Johnson MJ, Bland JM, Oxberry SG, et al. Clinically Important Differences in the Intensity of Chronic Refractory Breathlessness. Journal of Pain and Symptom Management. 2013;46(6):957-963. doi: 10.1016/j.jpainsymman.2013.01.011.

17. Currow DC, McDonald C, Oaten S, et al. Once-daily opiods for chronic dyspnea: a dose increment and pharmacovigilance study. Journal of pain and symptom management. 2011;42(3):388-99.

18. Gosport Independent Panel. Gosport War Memorial Hospital. The report of the Gosport Independent Panel. 2018.

19. Janssen DJ, Spruit MA, Uszko-Lencer NH, et al. Symptoms, comorbidities, and health care in advanced chronic obstructive pulmonary disease or chronic heart failure. J Palliat Med. 2011 Jun;14(6):735-43. doi: 10.1089/jpm.2010.0479. PubMed PMID: 21510771; eng.

20. Verberkt CA, van den Beuken-van Everdingen MHJ, Schols J, et al. Respiratory adverse effects of opioids for breathlessness: a systematic review and meta-analysis. The European respiratory journal. 2017 Nov;50(5). doi: 10.1183/13993003.01153-2017. PubMed PMID: 29167300; eng.

21. Graeme R, Jean B, James D. The New "Opioid Crisis": Scientific Bias, Media Attention, and Potential Harms for Patients with Refractory Dyspnea. Journal of palliative medicine. 2018;21(2):120-122. doi: 10.1089/jpm.2017.0619. PubMed PMID: 29393775.

22. Johnson MJ, Bland JM, Oxberry SG, et al. Opioids for chronic refractory breathlessness: patient predictors of beneficial response. The European respiratory journal. 2013 Sep;42(3):758-66. doi: 10.1183/09031936.00139812. PubMed PMID: 23258776; eng.

23. von Leupoldt A, Seemann N, Gugleva T, et al. Attentional distraction reduces the affective but not the sensory dimension of perceived dyspnea. Respiratory medicine. 2007 Apr;101(4):839-44. doi: 10.1016/j.rmed.2006.06.033. PubMed PMID: 16971103; eng.

24. von Leupoldt A, Taube $K$, Schubert-Heukeshoven $S$, et al. Distractive auditory stimuli reduce the unpleasantness of dyspnea during exercise in patients with COPD. Chest. 2007 Nov;132(5):1506-12. doi: 10.1378/chest.07-1245. PubMed PMID: 17890458; eng.

25. von Leupoldt A, Dahme B. Differentiation between the sensory and affective dimension of dyspnea during resistive load breathing in normal subjects. Chest. 2005 Nov;128(5):3345-9. doi: 10.1378/chest.128.5.3345. PubMed PMID: 16304282; eng.

26. Banzett RB, O'Donnell CR, Guilfoyle TE, et al. Multidimensional Dyspnea Profile: an instrument for clinical and laboratory research. The European respiratory journal. 2015 Jun;45(6):1681-91. doi: 10.1183/09031936.00038914. PubMed PMID: 25792641; PubMed Central PMCID: PMCPMC4450151. eng.

27. Papp LA, Weiss JR, Greenberg HE, et al. Sertraline for chronic obstructive pulmonary disease and comorbid anxiety and mood disorders. The American journal of psychiatry. 1995 Oct;152(10):1531. PubMed PMID: 7573598; eng.

28. Smoller JW, Pollack MH, Systrom D, et al. Sertraline effects on dyspnea in patients with obstructive airways disease. Psychosomatics. 1998 Jan-Feb;39(1):24-9. doi: 10.1016/s00333182(98)71377-5. PubMed PMID: 9538672; eng.

29. Watts GJ, Clark K, Agar M, et al. Study protocol: a phase III randomised, double-blind, parallel arm, stratified, block randomised, placebo-controlled trial investigating the clinical effect and cost-effectiveness of sertraline for the palliative relief of breathlessness in people with chronic breathlessness. BMJ Open. 2016;6(11). doi: 10.1136/bmjopen-2016-013177. 
30. Lovell N, Bajwah S, Maddocks M, et al. Use of mirtazapine in patients with chronic breathlessness: A case series. Palliat Med. 2018 Jul 1:269216318787450. doi: 10.1177/0269216318787450. PubMed PMID: 30028237; eng.

31. Currow DC, Ekström M, Louw S, et al. Sertraline in symptomatic chronic breathlessness: a double blind, randomised trial. European Respiratory Journal. 2018. doi:

10.1183/13993003.01270-2018.

32. Eisner MD, Blanc PD, Yelin EH, et al. Influence of anxiety on health outcomes in COPD. Thorax. 2010 Mar;65(3):229-34. doi: 10.1136/thx.2009.126201. PubMed PMID: 20335292; PubMed Central PMCID: PMCPMC3111227. eng.

33. Higginson IJ, Bausewein C, Reilly CC, et al. An integrated palliative and respiratory care service for patients with advanced disease and refractory breathlessness: a randomised controlled trial. The Lancet Respiratory Medicine. 2014 2014/12/01/;2(12):979-987. doi: https://doi.org/10.1016/S2213-2600(14)70226-7.

34. Bausewein C, Booth S, Gysels M, et al. Understanding breathlessness: cross-sectional comparison of symptom burden and palliative care needs in chronic obstructive pulmonary disease and cancer. Journal of palliative medicine. 2010 Sep;13(9):1109-18. doi: 10.1089/jpm.2010.0068. PubMed PMID: 20836635; eng.

35. Coultas DB, Edwards DW, Barnett B, et al. Predictors of Depressive Symptoms in Patients with COPD and Health Impact. COPD: Journal of Chronic Obstructive Pulmonary Disease. 2007 2007/01/01;4(1):23-28. doi: 10.1080/15412550601169190.

36. de Voogd JN, Wempe JB, Koeter GH, et al. Depressive symptoms as predictors of mortality in patients with COPD. Chest. 2009 Mar;135(3):619-625. doi: 10.1378/chest.08-0078. PubMed PMID: 19029432; eng.

37. Blazer DG, Hybels CF. Shortness of breath as a predictor of depressive symptoms in a community sample of older adults. International journal of geriatric psychiatry. 2010 Oct;25(10):1080-4. doi: 10.1002/gps.2477. PubMed PMID: 20872930; PubMed Central PMCID: PMCPMC3039879. eng.

38. Atlantis E, Fahey $\mathrm{P}$, Cochrane $\mathrm{B}$, et al. Bidirectional associations between clinically relevant depression or anxiety and COPD: a systematic review and meta-analysis. Chest. 2013 Sep;144(3):766-777. doi: 10.1378/chest.12-1911. PubMed PMID: 23429910; eng.

39. Kunik ME, Roundy $K$, Veazey $C$, et al. Surprisingly high prevalence of anxiety and depression in chronic breathing disorders. Chest. 2005 Apr;127(4):1205-11. doi: 10.1378/chest.127.4.1205. PubMed PMID: 15821196; eng.

40. Laviolette L, Laveneziana P. Dyspnoea: a multidimensional and multidisciplinary approach. Eur Respir J. 2014 Jun;43(6):1750-1762. doi: 10.1183/09031936.00092613. PubMed PMID: 24525437; Eng.

41. von Leupoldt A, Mertz C, Kegat $S$, et al. The impact of emotions on the sensory and affective dimension of perceived dyspnea. Psychophysiology. 2006 Jul;43(4):382-6. doi: 10.1111/j.1469-8986.2006.00415.x. PubMed PMID: 16916434; eng.

42. Reilly $\mathrm{CC}$, Ward $\mathrm{K}$, Jolley $\mathrm{CJ}$, et al. Neural respiratory drive, pulmonary mechanics and breathlessness in patients with cystic fibrosis. Thorax. 2011 Mar;66(3):240-6. doi: 10.1136/thx.2010.142646. PubMed PMID: 21285244; eng.

43. Jolley CJ, Luo YM, Steier J, et al. Neural respiratory drive and breathlessness in COPD. The European respiratory journal. 2015 Feb;45(2):355-64. doi: 10.1183/09031936.00063014. PubMed PMID: 25323229; eng.

44. Jolley CJ, Moxham J. Dyspnea Intensity: A Patient-reported Measure of Respiratory Drive and Disease Severity. American journal of respiratory and critical care medicine. 2016 Feb 1;193(3):236-8. doi: 10.1164/rccm.201510-1929ED. PubMed PMID: 26829421; eng.

45. Faisal A, Alghamdi BJ, Ciavaglia CE, et al. Common Mechanisms of Dyspnea in Chronic Interstitial and Obstructive Lung Disorders. American journal of respiratory and critical care medicine. 2015 2016/02/01;193(3):299-309. doi: 10.1164/rccm.201504-08410C. 
46. Chen Z, Eldridge FL, Wagner PG. Respiratory-associated rhythmic firing of midbrain neurones in cats: relation to level of respiratory drive. The Journal of Physiology. 1991 Jun;437:305-25. PubMed PMID: 1890637; PubMed Central PMCID: PMCPMC1180049. eng.

47. Chen Z, Eldridge FL, Wagner PG. Respiratory-associated thalamic activity is related to level of respiratory drive. Respir Physiol. 1992 Oct;90(1):99-113. PubMed PMID: 1455102; eng.

48. Banzett RB, Mulnier HE, Murphy K, et al. Breathlessness in humans activates insular cortex. Neuroreport. 2000 Jul 14;11(10):2117-20. PubMed PMID: 10923655; eng.

49. von Leupoldt A, Sommer T, Kegat $S$, et al. The unpleasantness of perceived dyspnea is processed in the anterior insula and amygdala. American journal of respiratory and critical care medicine. 2008 May 1;177(9):1026-32. doi: 10.1164/rccm.200712-18210C. PubMed PMID: 18263796; eng.

50. Peiffer C, Costes N, Hervé P, et al. Relief of Dyspnea Involves a Characteristic Brain Activation and a Specific Quality of Sensation. American journal of respiratory and critical care medicine. 2008 2008/02/15;177(4):440-449. doi: 10.1164/rccm.200612-17740C.

51. Faull OK, Hayen A, Pattinson KTS. Breathlessness and the body: Neuroimaging clues for the inferential leap. Cortex; a journal devoted to the study of the nervous system and behavior. 2017 Oct;95:211-221. doi: 10.1016/j.cortex.2017.07.019. PubMed PMID: 28915367; PubMed Central PMCID: PMCPMC5637166. eng.

52. Faull OK, Pattinson KT. The cortical connectivity of the periaqueductal gray and the conditioned response to the threat of breathlessness. eLife. 2017 Feb 17;6. doi: 10.7554/eLife.21749. PubMed PMID: 28211789; PubMed Central PMCID: PMCPMC5332157. eng.

53. Pattinson KT, Johnson MJ. Neuroimaging of central breathlessness mechanisms. Current opinion in supportive and palliative care. 2014 Sep;8(3):225-33. doi:

10.1097/spc.0000000000000069. PubMed PMID: 25029392; eng.

54. Herzog M, Sucec J, Van Diest I, et al. Observing dyspnoea in others elicits dyspnoea, negative affect and brain responses. European Respiratory Journal. 2018;51(4). doi: 10.1183/13993003.02682-2017.

55. Johnson MJ, Simpson MI, Currow DC, et al. Magnetoencephalography to investigate central perception of exercise-induced breathlessness in people with chronic lung disease: a feasibility pilot. BMJ Open. 2015 Jun 10;5(6):e007535. doi: 10.1136/bmjopen-2014-007535. PubMed PMID: 26063567; PubMed Central PMCID: PMCPMC4574009. eng.

56. Cannon WB. Bodily changes in pain, fear, hunger, and rage. New York, Appleton. 1929.

57. Stahl SM. Stahl's essential psychopharmacology: neuroscientific basis and practical applications. Cambridge university press; 2013.

58. Janak PH, Tye KM. From circuits to behaviour in the amygdala. Nature. 2015;517(7534):284292. doi: 10.1038/nature14188. PubMed PMID: PMC4565157.

59. Van den Bergh O, Witthoft M, Petersen S, et al. Symptoms and the body: Taking the inferential leap. Neuroscience and biobehavioral reviews. 2017 Mar;74(Pt A):185-203. doi: 10.1016/j.neubiorev.2017.01.015. PubMed PMID: 28108416; eng.

60. Herigstad $M$, Hayen $A$, Evans $E$, et al. Dyspnea-related cues engage the prefrontal cortex: evidence from functional brain imaging in COPD. Chest. 2015 Oct;148(4):953-961. doi: 10.1378/chest.15-0416. PubMed PMID: 26134891; PubMed Central PMCID: PMCPMC4594628. eng.

61. Herigstad M, Faull OK, Hayen A, et al. Treating breathlessness via the brain: changes in brain activity over a course of pulmonary rehabilitation. The European respiratory journal. 2017 Sep;50(3). doi: 10.1183/13993003.01029-2017. PubMed PMID: 28899937; PubMed Central PMCID: PMCPMC5678895 erj.ersjournals.com. eng.

62. Pineles SL, Vogt DS, Orr SP. Personality and fear responses during conditioning: Beyond extraversion. Personality and individual differences. 2009 Jan;46(1):48-53. doi: 
10.1016/j.paid.2008.09.003. PubMed PMID: 20046207; PubMed Central PMCID: PMCPMC2598742. eng.

63. Yang J, Yin Y, Svob C, et al. Amygdala Atrophy and Its Functional Disconnection with the Cortico-Striatal-Pallidal-Thalamic Circuit in Major Depressive Disorder in Females. PLoS ONE. 2017;12(1). doi: 10.1371/journal.pone.0168239. PubMed PMID: 28107446; PubMed Central PMCID: PMCPMC5249227. eng.

64. Bremner JD, Randall P, Scott TM, et al. MRI-based measurement of hippocampal volume in patients with combat-related posttraumatic stress disorder. The American journal of psychiatry. 1995 Jul;152(7):973-81. doi: 10.1176/ajp.152.7.973. PubMed PMID: 7793467; PubMed Central PMCID: PMCPMC3233767. eng.

65. Buckley TC, Blanchard EB, Neill WT. Information processing and PTSD: a review of the empirical literature. Clinical psychology review. 2000 Nov;20(8):1041-65. PubMed PMID: 11098399; eng.

66. Feldman JL, Mitchell GS, Nattie EE. Breathing: rhythmicity, plasticity, chemosensitivity. Annual review of neuroscience. 2003;26(1):239-266.

67. Reid G, Rand M. Physiological actions of the partially purified serum vasoconstrictor (serotonin). Australian Journal of Experimental Biology \& Medical Science. 1951;29(6).

68. Douglas WW, Toh CC. The respiratory stimulant action of 5-hydroxytryptamine (serotonin) in the dog. The Journal of Physiology. 1953 May 28;120(3):311-8. PubMed PMID: 13070202; PubMed Central PMCID: PMCPMC1365955. eng.

69. Michelson AL, Hollander W, Lowell FC. The effect of 5-hydroxytryptamine (serotonin) on the respiration on nonasthmatic and asthmatic subjects. I. The Journal of laboratory and clinical medicine. 1958 Jan;51(1):57-62. PubMed PMID: 13514208; eng.

70. Parks VJ, Sandison AG, Skinner SL, et al. The stimulation of respiration by 5hydroxytryptamine in man. The Journal of Physiology. 1960 May;151:342-51. PubMed PMID: 14430544; PubMed Central PMCID: PMCPMC1363242. eng.

71. Hilaire $\mathrm{G}$, Voituron $\mathrm{N}$, Menuet $\mathrm{C}$, et al. The role of serotonin in respiratory function and dysfunction. Respiratory physiology \& neurobiology. 2010 Nov 30;174(1-2):76-88. doi: 10.1016/j.resp.2010.08.017. PubMed PMID: 20801236; PubMed Central PMCID: PMCPMC2993113. eng.

72. Richter DW, Manzke T, Wilken B, et al. Serotonin receptors: guardians of stable breathing. Trends in molecular medicine. 2003 Dec;9(12):542-8. PubMed PMID: 14659469; eng.

73. Bocchio M, McHugh SB, Bannerman DM, et al. Serotonin, Amygdala and Fear: Assembling the Puzzle. Frontiers in Neural Circuits. 2016;10:24. doi: 10.3389/fncir.2016.00024. PubMed PMID: PMC4820447.

74. Grady CL, Siebner HR, Hornboll B, et al. Acute pharmacologically induced shifts in serotonin availability abolish emotion-selective responses to negative face emotions in distinct brain networks. European neuropsychopharmacology : the journal of the European College of Neuropsychopharmacology. 2013 May;23(5):368-78. doi: 10.1016/j.euroneuro.2012.06.003. PubMed PMID: 22739125; eng.

75. Bertani A, Caldirola D, Bussi R, et al. The 35\% CO2 hyperreactivity and clinical symptomatology in patients with panic disorder after 1 week of treatment with citalopram: an open study. Journal of clinical psychopharmacology. 2001 Jun;21(3):262-7. PubMed PMID: 11386488; eng.

76. Perna G, Bertani A, Caldirola D, et al. Antipanic drug modulation of $35 \% \mathrm{CO} 2$ hyperreactivity and short-term treatment outcome. Journal of clinical psychopharmacology. 2002 Jun;22(3):300-8. PubMed PMID: 12006901; eng.

77. Goddard AW, Ball SG, Martinez J, et al. Current perspectives of the roles of the central norepinephrine system in anxiety and depression. Depression and anxiety. 2010 Apr;27(4):339-50. doi: 10.1002/da.20642. PubMed PMID: 19960531; eng. 
78. Kitayama I, Yaga T, Kayahara T, et al. Long-term stress degenerates, but imipramine regenerates, noradrenergic axons in the rat cerebral cortex. Biological psychiatry. 1997 Oct 15;42(8):687-96. PubMed PMID: 9325562; eng.

79. Liu Y, Ishida $Y$, Shinoda $K$, et al. Effects of repeated stress on regeneration of serotonergic and noradrenergic axons in the cerebral cortex of adult rats. Neuroscience letters. $2003 \mathrm{Mar}$ 27;339(3):227-30. PubMed PMID: 12633894; eng.

80. Lambert $\mathrm{G}$, Johansson $\mathrm{M}$, Agren $\mathrm{H}$, et al. Reduced brain norepinephrine and dopamine release in treatment-refractory depressive illness: evidence in support of the catecholamine hypothesis of mood disorders. Archives of general psychiatry. 2000 Aug;57(8):787-93. PubMed PMID: 10920468; eng.

81. Tank AW, Lee Wong D. Peripheral and central effects of circulating catecholamines. Comprehensive Physiology. 2015 Jan;5(1):1-15. doi: 10.1002/cphy.c140007. PubMed PMID: 25589262; eng.

82. Westfall TC, Westfall DP. Neurotransmission: the autonomic and somatic motor nervous system. Goodman and Gilman's The Pharmacological Basis of Therapeutics, 12th ed Edited by L Bruton New York: McGraw Hill. 2011:171-218.

83. Mahler DA, Murray JA, Waterman LA, et al. Endogenous opioids modify dyspnoea during treadmill exercise in patients with COPD. The European respiratory journal. 2009 Apr;33(4):771-7. doi: 10.1183/09031936.00145208. PubMed PMID: 19213787; eng.

84. Mahler DA, Gifford AH, Gilani A, et al. Antagonism of substance P and perception of breathlessness in patients with chronic obstructive pulmonary disease. Respiratory physiology \& neurobiology. 2014 Jun 1;196:1-7. doi: 10.1016/j.resp.2014.02.008. PubMed PMID: 24582719; eng.

85. Cipriani A, Furukawa TA, Salanti G, et al. Comparative efficacy and acceptability of 21 antidepressant drugs for the acute treatment of adults with major depressive disorder: a systematic review and network meta-analysis. The Lancet. doi: 10.1016/S01406736(17)32802-7.

86. Kent JM. SNaRIs, NaSSAs, and NaRIs: new agents for the treatment of depression. Lancet (London, England). 2000 Mar 11;355(9207):911-8. doi: 10.1016/s0140-6736(99)11381-3. PubMed PMID: 10752718; eng.

87. Montgomery SA. Safety of mirtazapine: a review. International clinical psychopharmacology. 1995 Dec;10 Suppl 4:37-45. PubMed PMID: 8930008; eng.

88. de Boer T, Maura G, Raiteri M, et al. Neurochemical and autonomic pharmacological profiles of the 6-aza-analogue of mianserin, org 3770 and its enantiomers. Neuropharmacology. 1988 1988/04/01/;27(4):399-408. doi: https://doi.org/10.1016/0028-3908(88)90149-9.

89. De Boer T, Ruigt $\mathrm{G}$, Berendsen $\mathrm{H}$. The $\alpha 2$-selective adrenoceptor antagonist org 3770 (mirtazapine, Remeron ${ }^{\circledR}$ ) enhances noradrenergic and serotonergic transmission. Human Psychopharmacology: Clinical and Experimental. 1995;10(S2).

90. Mason M, Welsh EJ, Smith I. Drug therapy for obstructive sleep apnoea in adults. The Cochrane database of systematic reviews. 2013 May 31(5):Cd003002. doi: 10.1002/14651858.CD003002.pub3. PubMed PMID: 23728641; eng.

91. Barnett K, Mercer SW, Norbury M, et al. Epidemiology of multimorbidity and implications for health care, research, and medical education: a cross-sectional study. Lancet (London, England). 2012 Jul 7;380(9836):37-43. doi: 10.1016/s0140-6736(12)60240-2. PubMed PMID: 22579043; eng.

92. Kasper S. Clinical efficacy of mirtazapine: a review of meta-analyses of pooled data. International clinical psychopharmacology. 1995 Dec;10 Suppl 4:25-35. PubMed PMID: 8930007; eng.

93. Watanabe N, Omori IM, Nakagawa A, et al. Mirtazapine versus other antidepressive agents for depression. The Cochrane database of systematic reviews. 2011 Dec 7(12):Cd006528. 
doi: 10.1002/14651858.CD006528.pub2. PubMed PMID: 22161405; PubMed Central PMCID: PMCPMC4158430. eng.

94. Ribeiro L, Busnello JV, Kauer-Sant'Anna M, et al. Mirtazapine versus fluoxetine in the treatment of panic disorder. Brazilian journal of medical and biological research $=$ Revista brasileira de pesquisas medicas e biologicas. 2001 Oct;34(10):1303-7. PubMed PMID: 11593305; eng.

95. Vollm B, Richardson P, McKie S, et al. Serotonergic modulation of neuronal responses to behavioural inhibition and reinforcing stimuli: an fMRI study in healthy volunteers. The European journal of neuroscience. 2006 Jan;23(2):552-60. doi: 10.1111/j.14609568.2005.04571.x. PubMed PMID: 16420462; eng.

96. Arnone D, Horder J, Cowen PJ, et al. Early effects of mirtazapine on emotional processing. Psychopharmacology. 2009 May;203(4):685-91. doi: 10.1007/s00213-008-1410-6. PubMed PMID: 19031070; eng.

97. Rawlings NB, Norbury R, Cowen PJ, et al. A single dose of mirtazapine modulates neural responses to emotional faces in healthy people. Psychopharmacology. 2010 Dec;212(4):62534. doi: 10.1007/s00213-010-1983-8. PubMed PMID: 20809213; eng.

98. Komulainen E, Heikkila R, Meskanen K, et al. A single dose of mirtazapine attenuates neural responses to self-referential processing. Journal of psychopharmacology (Oxford, England). 2016 Jan;30(1):23-32. doi: 10.1177/0269881115616384. PubMed PMID: 26577062; eng.

99. Komulainen E, Glerean E, Meskanen K, et al. Single dose of mirtazapine modulates wholebrain functional connectivity during emotional narrative processing. Psychiatry research. 2017 May 30;263:61-69. doi: 10.1016/j.pscychresns.2017.03.009. PubMed PMID: 28366871; eng.

100. Gysels $\mathrm{MH}$, Higginson IJ. The lived experience of breathlessness and its implications for care: a qualitative comparison in cancer, COPD, heart failure and MND. BMC Palliative Care. 2011;10:15-15. doi: 10.1186/1472-684X-10-15. PubMed PMID: PMC3206451.

101. Edmonds $P$, Karlsen S, Khan S, et al. A comparison of the palliative care needs of patients dying from chronic respiratory diseases and lung cancer. Palliat Med. 2001 Jul;15(4):287-95. doi: 10.1191/026921601678320278. PubMed PMID: 12054146; eng. 